NIHON REOROJĪ GAKKAISHI Vol. 23, No. 2, 109 113 (1995)

(C)1995 The Society of Rheology, Japan

\title{
A New Measurement Method for Viscoelastic Properties of \\ Disperse Systems by Fourier Transform Rheometer
}

\author{
Takanobu UEDA
}

Nippon Paint Co. Ltd.

19-17, Ikedanakamachi, Neyagawa City, Osaka, 572 Japan

\begin{abstract}
This paper proposes a new method for measuring frequency dependence of $G^{\prime}$ and $G^{\prime \prime}$, using a coaxial cone-plate type rheometer oscillated by multifrequency wave, named Fourier Transform Rheometer (FT-RM). The experimental results manifest that this FT-RM is much more superior than the conventional dynamic method for obtainning the freaquency dependence curves of $G^{\prime}$ and $G^{\prime \prime}$ for disperse systems in transition state. The FT-RM is more acculate for the measurements in curing process of automobile primer paint than a pulse method using a Raised Cosine Pulse. A gel point of the coated layer is specified by the frequency dependence curves of $G^{\prime}$ and $G^{\prime \prime}$ at various temperatures. Effect of shearing on the viscoelastic properties is also examined in silica dispersions using an electromagnetic induction torque transducer. For the disperse systems including chemically modified hydrophobic silica with a good affinity for vehicle, $G^{\prime}$ increases with shearing process. On the other hand for the suspensions of untreated silica with poor affinity for vehicle, $G^{\prime}$ decreases with shearing process.

Key Words : Fourier Transform Rheometer/Multifrequency Wave/Disperse Systems/Frequency Dependence Curve
\end{abstract}

\section{合成波を用いた新しい粘弾性の周波数同時測定法(FT-RM) の顔料分散系への応用 \\ (Cone-plate Type Fourier Transform Rheometer の開発)

\author{
上田 隆宣
}

\author{
（原稿受理:1995年2月8日）
}

\section{1. 粕 言}

粘弾性関数の周波数分散は分散系における粒子の分散状態を知 る上で大变重要である. しかし，周波数分散の測定は比較的長時 間を要するために，この方法を硬化反応や分散状態の変化を伴う 系に適用することは必ずしあ適当とはいえない，そこで，線形性 を考慮したうえで様々な周波数成分を含んだパルス波による測定 が提案されている1),2).

パルス測定は与える歪みが小さいために分散系の粒子分散状態
に影響をあたえずに測定できるという意味では大変有効である. しかし, 測定装置面で応力検出器の安定性, 剛性の高さ, 分解能 の高さなどが要求される. また, パルスを加えてから緩和測定の 終了まで系が変化しないことが前提であるために, 塗料の硬化過 程や不安定な分散系において分散挙動の測定にはパルス法の適用 は困難であった.

そこで, 本報告ではフーリエ合成波を用いた新しい粘弾性の周 波数分散同時測定法(Fourier Transform Rheometer)を提案 し，測定の意味，適用範囲などのついて報告する.

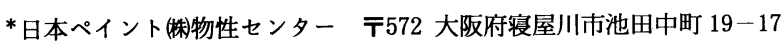




\section{2. 測定原理}

Raised Cosine Pulse (RCP)法の測定理論で磯田らが述べて いるように1), 正弦ひずみを $r(t)=\gamma_{0} e^{i \omega_{0} t}$, それによって生ずる 正弦応力を $\sigma(t)=\sigma_{0} e^{i\left(\omega_{0} t+\delta\right)}$ で表すとき, コーン・プレート型 粘弾性測定装置のコーン半径およびコーン角度をそれぞれ $r$ およ び $\varphi$ とした場合複素剛性率 $G^{*}$ は次式で与えられる.

$$
\begin{aligned}
G^{*}(i \omega) & =\frac{\sigma(t)}{r(t)}=\frac{3 \varphi}{2 \pi r^{3}} \frac{\sigma_{0}}{r_{0}} e^{i \delta} \\
& =\frac{3 \varphi}{2 \pi r^{3}} \frac{\sigma_{0}}{r_{0}}(\cos \delta+i \sin \delta)
\end{aligned}
$$

これは従来の動的測定法の原理である.ここで，線形粘弾性では Boltzmann の重畳原理式 (2) が成立する.

$$
\sigma(t)=\int_{\infty}^{t} \varphi\left(t-t^{\prime}\right) \frac{d r\left(t^{\prime}\right)}{d t^{\prime}} d t^{\prime}
$$

ここに, 変位 $\gamma(t)=\gamma_{0} e^{i \omega t}$ を代入すれば,

$$
\sigma(t)=i \omega \gamma(t) \int_{0}^{\infty} \varphi_{s} e^{-i \omega s} d s
$$

ただし $s=t-t^{\prime}$ である.ここで

$$
\Phi(i \omega)=\int_{0}^{\infty} \varphi_{s} e^{-i \omega s} d s
$$

と置き, 式(1)と比較すると

$$
G^{*}(i \omega)=\frac{\sigma(t)}{r(t)}=i \omega \Phi(i \omega)
$$

となる.ささ，Boltzmannの重畳原理式をフーリエ変換すると

$$
\Sigma(i \omega)=\Phi(i \omega) i \omega \Gamma(i \omega)
$$

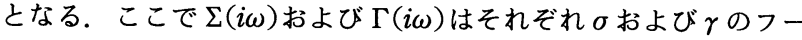
リエ変換である.

式 (5) と比較すると

$$
G^{*}(i \omega)=\frac{\Sigma(i \omega)}{\Gamma(i \omega)}
$$

となる. したがって, 線形領域において複素剛性率は応力と変位 のフーリエ変換の比として与えられる. 言い換えれば, 複数の周 波数が重なり合った变位を与えても各周波数での応答は単純に重 ね合わせた波形となり他の周波数の変位が影響を与えないという ことになる．RCP 法では $\Gamma(i \omega)$ を 1 となるような関数として Raised Cosine Pulse を用いているが，FT-RM 法ではひずみと して次式(8)で示すようなフーリエ合成波を利用する.

$$
\gamma(t)=\sum_{n=0}^{m} \gamma_{\eta} \sin \left(2 \pi 2^{n} \omega t\right)
$$

これにより, 基本周波数の $\gamma(t)=\gamma_{0} \sin (2 \pi \omega t)$ のひずみに高次の 周波数のひずみを重ね合わせた合成波で測定を行う.

$\mathrm{RCP}$ 法に代表されるパルス法は与えた周波数より低周波成分 を測定できるので，非常に微小なひずみによって測定周波数より 低周波数領域の同時測定ができることが最大の特徴である.

FT-RM 法では基本周波数より高い周波数領域の同時測定とな る. 一方，パルス法は測定に利用するパルスの周波数より低周波 数領域を測定するので, 測定される周波数領域ではひずみ, 応力 ともに 1 周期分は含まれない，すなわち，応力の一部から全体を 推定していることになる.

FT-RM 法では合成波の基本周波数より高周波領域を測定して いるために測定周波数すべての周領域で 1 周期以上のひずみと 応力を完全な形で測定している. したがって, 測定系の状態が変
化する場合にはパルス法に比べFT-RM 法が有利になるあのと考 えられる.

\section{3. 測定装置}

Fig. 1は FT-RM 法の確認のために利用した岩本製作所製のレ オペキシーアナライザーRPX-705 のブロック図である．本装置 は駆動部分がサーボモーター制御であるため駆動制御用 H-68 で プログラム制御することで合成波を作りだしている.ただし, 本 波形のためのデータの分解能が 1 周期あたり 128 点しかないた めに最大であ 16 次高調波が限界である. また, 余弦合成波は矩形 波に近くなるために駆動に無理が生じるために正弦合成波を用い る方が適していた。

Fig. 2は顔料分散系での凝集構造と粘性挙動の関連を調べる目 的で試作したレオメーターMR3 を改造したあのである.

ソリキッドメーターMR3 は，コーンプレート型レオメーター で, 下部のプレート部がパルスモーター制御で定常回転したり振 動したりするようになっており，トルクは上部コーン側に取り付 けたワイヤーの捱じり角を変位センサーを用いて検知するか， あ るいはトルクトランスヂューザーで検知する．このトルク検知部 分にFig. 3に示すように永久磁石とコイルを組み合わせて, 位置 センサーを組み込んだ, 電磁誘導式のドライブユニットを利用し た.

電磁誘導式ドライブユニットは位置センサーの情報を電磁コイ ルの電流值にフィードバックしながらトルク検知を行う。すなわ

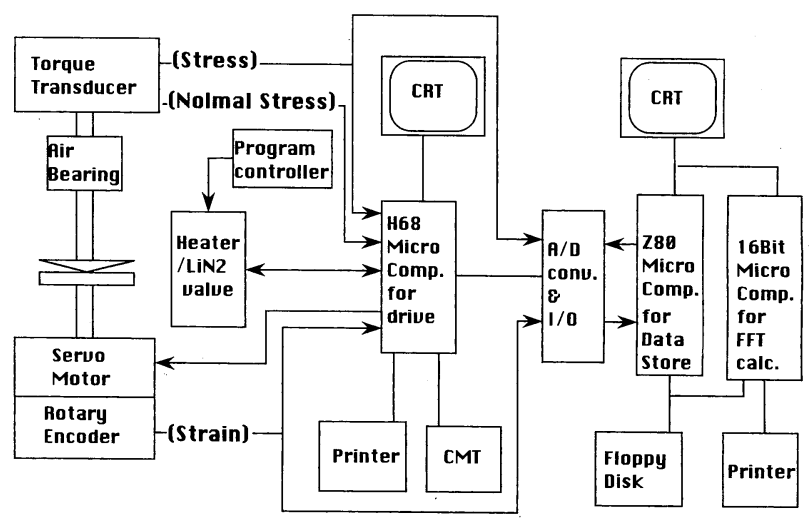

Fig. 1 Block diagram of cone-plate type fourier transform rheometer

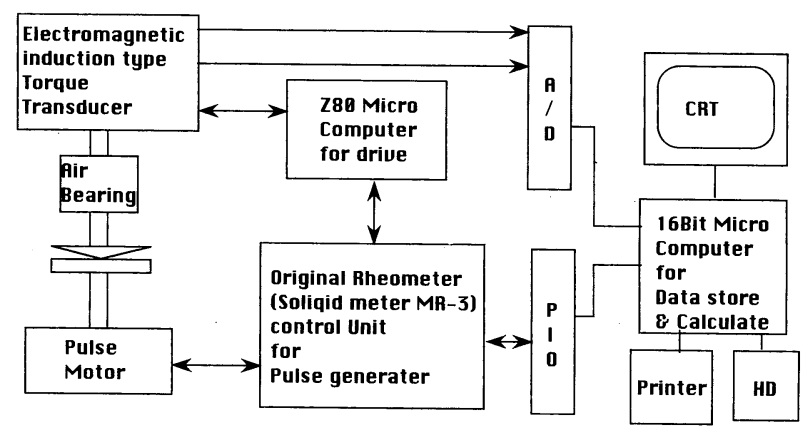

Fig. 2 Block diagram of cone-plate \& electromagnetic induction type fourier transform rheometer. 


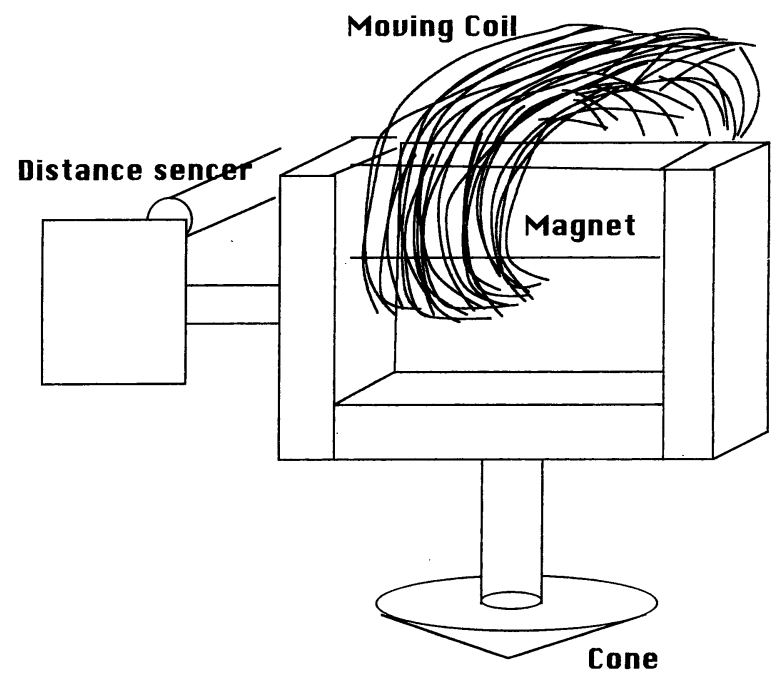

Fig. 3 Torque tranducer of electromagnetic induction type drive unit.

ち, 位置をゼロに保つための電磁コイルの電流値からトルクを求 めるようになっている. したがって, 電磁コイルに正弦波の電流 值を与えることにより, 上部のコーン側だけで駆動とトルク検知 が可能になる.

電磁誘導式ドライブユニットの駆動分解能は 1024 点 /周期と したために 64 次高調波までの合成波形を作り出すことが可能で あった．ただし，フィードバック回路の遅れの限界から低粘度試 料では電磁誘導式ドライブユニットが発振してしまい測定が不可 能であった．下部プレート側の駆動部を利用することにより，剪 断直後の粘弾性変化を測定することが可能であった.

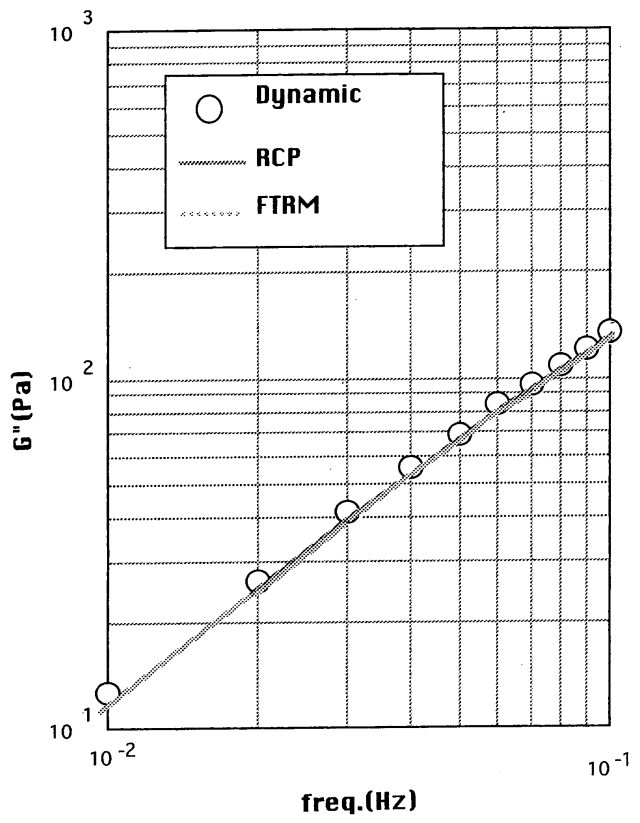

Fig. 4 Frequency dependence curves of $G^{\prime}$ for $20 \mathrm{wt} \% \mathrm{DEP}$ solution of PS.

\section{4. 結果}

(1) 高分子溶液系での検証

Fig. 4はポリスチレンの $20 \%$ フタル酸ジェチル溶液を代表的 なパルス法である RCP 法と式(9)に示す余弦合成波を用いた FT$\mathrm{RM}$ 法, 動的粘弾性測定の結果を示す. $0.01 \sim 0.1 \mathrm{~Hz}$ で動的測定 法, RCP 法, FT-RM 法ともによく一致している.

$$
\gamma(t)=\sum_{n=1}^{10} \gamma_{n} \cos \left(n \omega_{0} t\right)
$$

動的測定方法の最低安定測定回数を 3 周期とすると動的測定 法では約 900 秒, RCP 法では約 120 秒, FT-RM 法では約 300 秒 を要した。したがって, RCP 法, FT-RM 法ともに, 短時間で精 度よく測定できていることがわかる。

(2) 塗料硬化過程の測定

Fig. 5は自動車用中塗り塗料（ポリエステル/メラミン硬化系 で二酸化チタンを含有した塗料）の硬化過程での粘弾性測定結果 である. 動的測定の結果と FT-RM 法の結果は良く一致するが $\mathrm{RCP}$ 法では $0.01 \mathrm{~Hz}$ の測定で大きくずれていることがわかる.

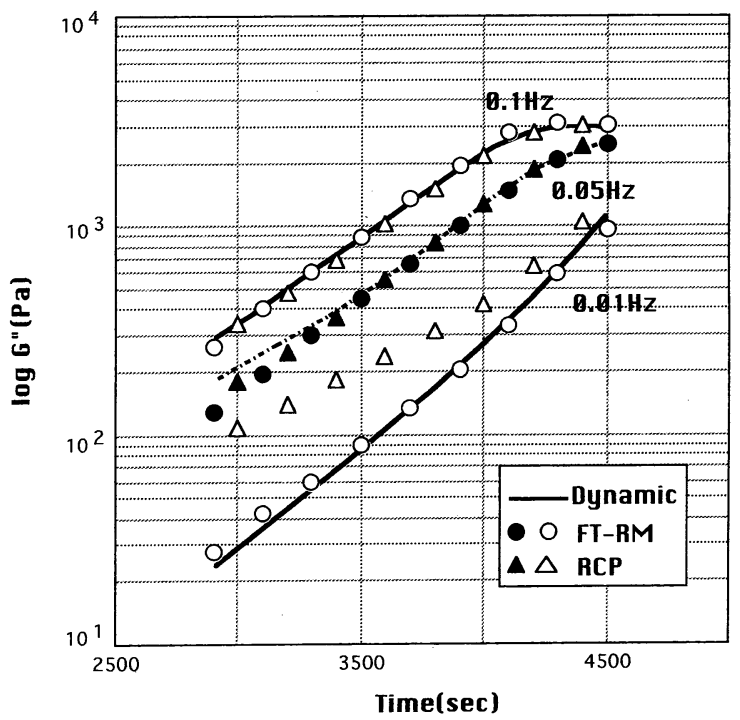

Fig. $5 \log G^{\prime \prime}$ plotted against time at frequencies $0.1,0.05$, $0.01 \mathrm{~Hz}$ in curing process.

$\mathrm{RCP}$ 法は, 応答は一定期間内に減衰しべースラインに戻るこ とを前提にした測定方法である。しかし，硬化過程のように状態 が変化してゆくような系においては応答がベースラインに戻らな い場合が多い，そのために一定時間後にベースラインに戻ったと してフーリエ変換を行うために低周波数領域の精度は極端におち てしまう.FTRM 法では合成波を利用した周期関数であり, フー リエ変換のために特別なデー夕処理を必要としないために, 硬化 過程のような状態変化を伴う場合の粘弾性測定において, 単周波 数による動的測定と同等の精度を得られているあのと考えられ る.

Fig. 6(a，b) は自動車中塗り塗料の硬化過程の測定結果を三次 元グラフ表示したあのである. 測定装置は岩本製作所製レオペキ シーアナライザーRPX-705, 測定治具はコーンプレート（径20 


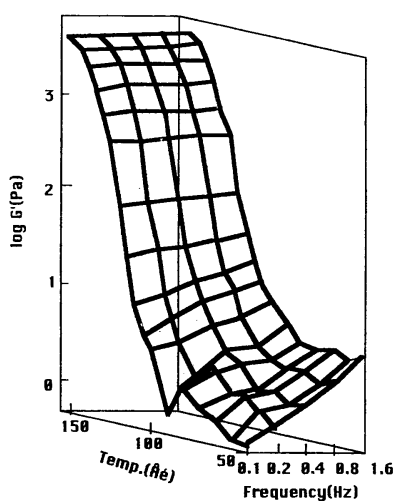

(a)

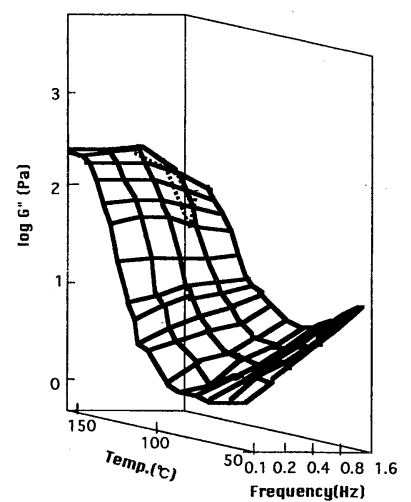

(b)
Fig. 6 Frequency dependence curves of $G^{\prime}$ (a) and $G^{\prime \prime}$ (b) against temperature for automotive primer in curing process.

$\mathrm{mm}$, 角度 $2^{\circ}$ )を用いた. 測定条件は基本周波数 $0.1 \mathrm{~Hz}$ に $0.2,0.4$, $0.8,1.6 \mathrm{~Hz}$ の波形を合成した正弦合成波を用い， $30^{\circ} \mathrm{C}$ から $150^{\circ} \mathrm{C}$ まで $2^{\circ} \mathrm{C} / \mathrm{min}$ で昇温測定を行った。

Fig. 6(a) は眝蔵剛性率 $G^{\prime}$ の $0.1 \sim 1.6 \mathrm{~Hz}$ の周波数分散の温度 依存性を示したもので, 硬化反応とともに貯蔵剛性率が高くな り，周波数に関係なく一定となっていく様子がよくわかる.

Fig. 6(b) は損失剛性率 $G^{\prime \prime}$ の $0.1 \sim 1.6 \mathrm{~Hz}$ の周波数分散の温度 依存性を示したもので, 硬化反応が進むと高周波領域から損失剛 性率が急激に減少して行く様子がよくわかる.

Fig. 6(a) とFig. 6(b)を重ね合わせてみると, $100^{\circ} \mathrm{C}$ 付近で $G^{\prime}, G^{\prime \prime}$ の周波数分散は一致しており,この温度が中塗り塗料のゲ ル化温度に近いことがわかる.

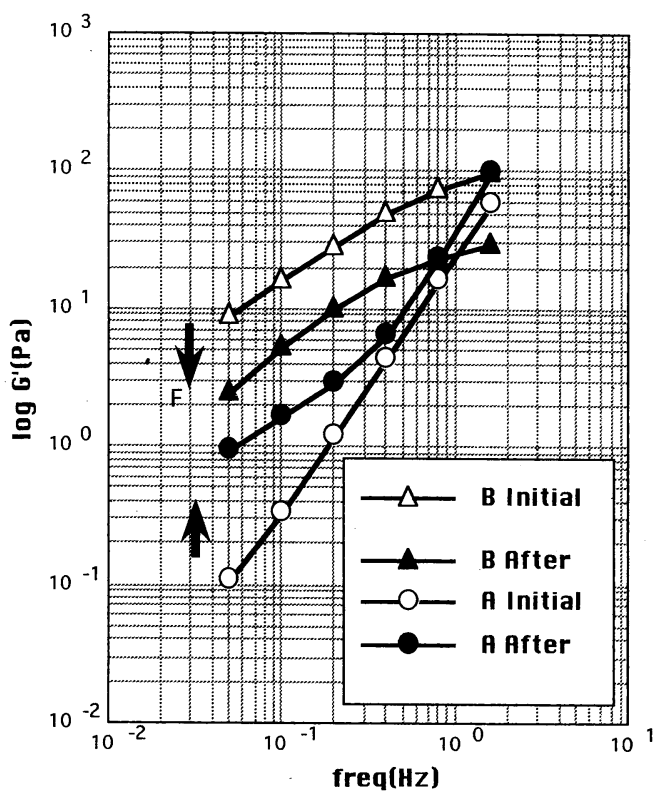

Fig. 7 Frequency dependence curves of $G^{\prime}$, in different shearing process for two types of $10 \mathrm{wt} \%$ silica dispersed acrỳlic resin.
(3) 剪断擋拌後の顔料分散状態変化の測定

顔料と分散媒の親和性を変えて顔料分散系の状態変化を知るた めに末処理のシリカ粉末(親和性) と蹯水処理したシリカ粉末をア クリル樹脂 $\left(M_{\mathrm{n}}=11000\right.$ で $\left.M_{\mathrm{w}} / M_{\mathrm{n}}=5.2\right)$ に $10 \mathrm{wt} \%$ 分散させた試 料を用いた。

測定装置は電磁誘導型トルク検知器を組み込んだ，レオロジ社 製のソリキドメータ MR 3, 測定治具はコーンプレート（径 30 $\mathrm{mm}$, 角度 20 )を用いた. 測定条件は温度 $25^{\circ} \mathrm{C}$ で, $100 / \mathrm{sec}$ の剪断 擋拌を 10 分間行い, 剪断停止直後からの粘弾性関数の時間依存 性を $0.5,0.1,0.2,0.4,0.8,1.6 \mathrm{~Hz}$ の正弦合成波を用いて測定した. 剪断擋拌時には電磁誘導型トルク検出器は駆動させず, 剪断停止 直後よりひずみ制御での合成波測定を行った.

Fig. 7 は剪断擋汼後の貯蔵剛性率 $G^{\prime}$ の周波数分散を示す. 塗 りつぶした記号は $100 / \mathrm{sec}$ の剪断停止直後の貯蔵剛性率の周波数 分散, 塗りつぶしていない記号はコーンプレートに充填して約 1 日放置した状態の貯蔵剛性率 $G^{\prime}$ の周波数分散である.

試料 $\mathrm{A}$ は疎水化処理したシリカ粉末を分散した親和性が良い 系, 試料 B は末処理のシリカ粉末を分散した親和性の悪い系を示 している. 親和性が悪い試料 B では周波数分散の形状はあまり変 わらず剪断停止直後に全周波数領域で眝蔵剛性率が低くなってい る. 親和性が良い試料 A では周波数分散の形状が大きく変わっ ており, 特に低周波数領域では剪断停止直後の貯蔵剛性率が高く なっている.

Fig. 8 は周波数 $0.1 \mathrm{~Hz}$ での貯蔵剛性率 $G^{\prime}$ の剪断停止直後から の回復挙動を示す. 親和性により剪断擋汼による剛性率増減の方 向性が正反対であり, 剪断停止後の回復は親和性が悪い場合の方 が速く，親和性の良い場合の回復は遅いことがわかる.

Fig. 9に親和性の違いによる剪断擋汼の影響の模式図を示す. 親和性の悪い場合は, 一般的にいわれているように，凝集体が剪

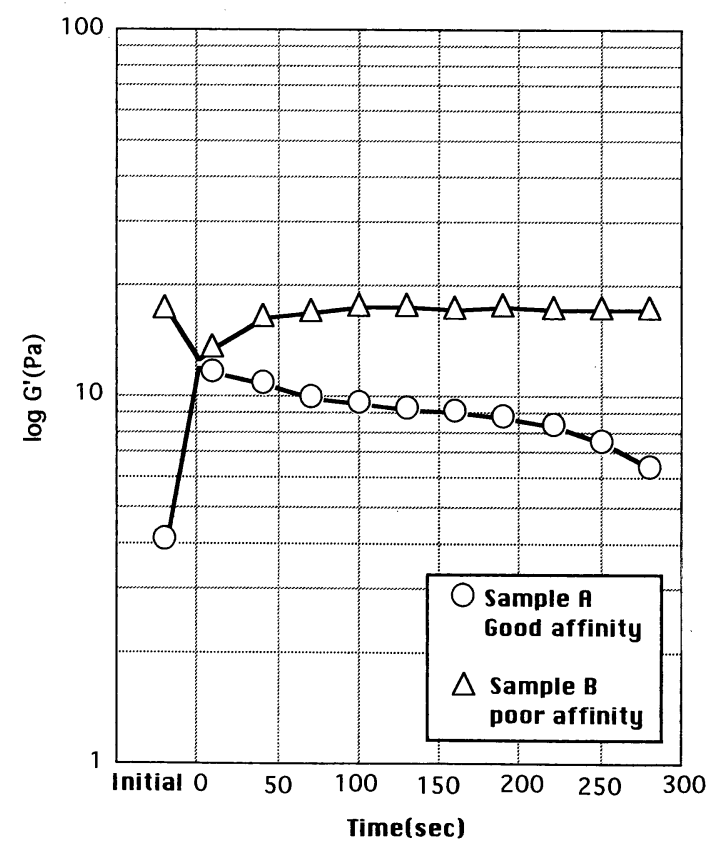

Fig. 8 Log $G^{\prime}$ plotted against time after cessation of shear for two types of silica dispersion. 

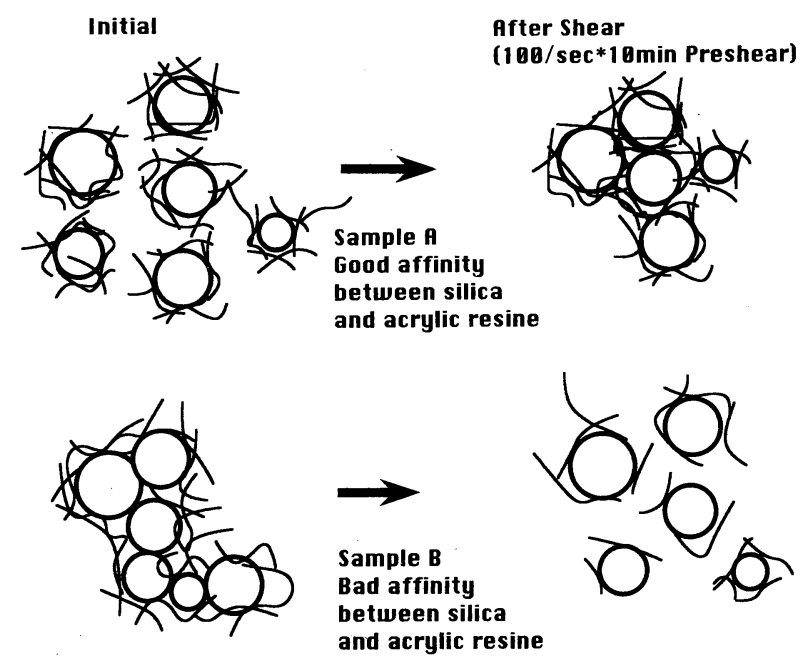

Fig. 9 Illustrations of the change of dispersing state by shear for two types of silica dispersion.

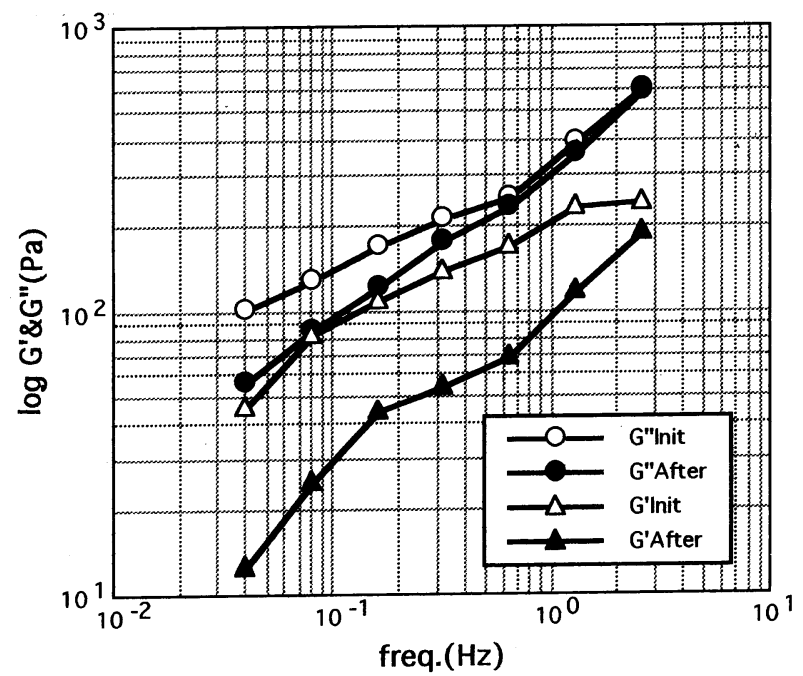

Fig. 10 Frequency dependence curves of $G^{\prime}$ and $G^{\prime \prime}$ in different shearing process for $10 \mathrm{wt} \%$ silica dispersed polyester $\operatorname{resin}\left(M_{\mathrm{n}}=3000\right)$.

断擋拌によって分散され剪断停止後は時間と共に凝集構造を作り ながらあとの状態に戻ると考えられる．親和性が良い場合には， シリカ粒子に樹脂が十分に吸着した状態で存在し，剪断擋拌に よって吸着樹脂が絡み合いにより凝集構造を作って低周波数での 眝蔵剛性率が大きくなっているものと考えられる.

Fig.10は塗料のたれ防止として利用される未処理のシリカ粉末 を塗料用ポリエステル樹脂 $\left(M_{\mathrm{n}}=3300, M_{\mathrm{w}} / M_{\mathrm{n}}=3.2\right)$ に $10 \mathrm{wt} \%$ 分散させた系の剪断擋拌前後の貯蔵剛性率 $G^{\prime}$ 之損失剛性率 $G^{\prime \prime}$ の 周波数分散の結果を示す. Fig. 11 は角速度 $0.25 \mathrm{rad} / \mathrm{sec}$ と 1.6

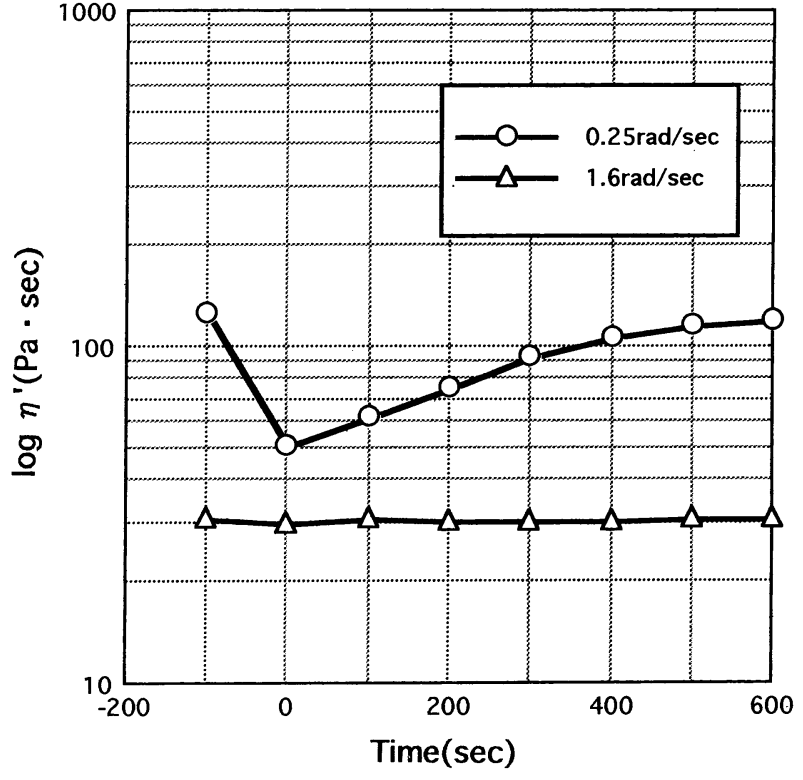

Fig. $11 \log \eta^{\prime}$ plotted against time after cessation of shear for silica dispersion at $0.25,1.6 \mathrm{rad} / \mathrm{sec}$.

$\mathrm{rad} / \mathrm{sec}$ のときの動的粘性率 $\eta^{\prime}$ の時間変化を示す．角速度が大き い場合には粘性率は剪断擋汼によって影響を受けず，角速度が小 さい場合には粘性率は剪断擋汼によって低下し回復する.これ は，低周波数領域では親和性が悪い系と同じ挙動を示していると 考えられる. シリカ粉末は顔料分散により表面に樹脂が充分吸着 した状態になり, 親和性の良い系と同じ状態に接近しようとして いるが, 吸着していない部分で凝集構造を作り剪断擋汼履歷を持 つあのと考えられる.

\section{5. 結言}

フーリエ合成波を用いた周波数分散同時測定法をコーンプレー ト型レオメーターに適用し, 塗料の硬化過程の周波数分散測定, シリカ粉末分散系の剪断擋拌による状態变化過程の周波数分散測 定を行い, 分散系の状態に関する有用なデータが得られることが わかった. すなわち, 硬化過程ではゲル化温度を特定することが 可能になり, 分散系の剪断擋拌履歴では粒子の分散状態とレオロ ジー的な性質の関連付けが可能になった.

（第 33 回, 第 35 回, 第 40 回レオロジー討論会にて講演）

\section{文献}

1）磯田武信, 大坪泰文, 安江高秀, 梅屋 薰, 日本レオロ ジー学会誌, 4, 133 (1976).

2) 堀米 操, 大坪泰文, 磯田武信, 日本レオロジー学会誌, 21, 97 (1993). 